\title{
The Art of Reviewing: Holding up quality in the scientific quality control system
}

Rajani Panchang ${ }^{1}$, A. Govin ${ }^{2}$ and C. Omuombo ${ }^{3}$

'Geology \& Palaeontology Group, Agharkar Research Institute, Pune, India; rajanipanchang@gmail.com

${ }^{2}$ MARUM Center for Marine Environmental Sciences, University of Bremen, Germany; ${ }^{2}$ Department of Geology, University of Nairobi, Kenya

E since the publication of the Philosophical Transactions of the Royal Society by Henry Oldenburg (1665, Fig. 1), scientists have acknowledged the importance of relaying research findings to a wider scientific community. Currently, publishing scientific findings in peerreviewed journals, brands the research work as "credible". These peer-reviewed scholarly articles improve the quality of science and are used as a metric for scientific performance, which is essential for career advancement. The Program Committee of the $2^{\text {nd }}$ PAGES YSM recognized the need to contribute to building capacity in the art of reviewing among young paleo-scientists. To this end, editors from prominent paleoscience journals, namely Nature Geoscience (Alicia Newton), Journal of Quaternary Science (Chris Turney) and Climate of the Past (Denis-Didier Rousseau) were invited to be part of a panel discussion highlighting the aims and process of peer-reviewing.

The discussion commenced with the importance of peer reviewing in science and the responsibility journal editors have to maintain the integrity and quality of science. Accordingly, the nominated reviewers bear the responsibility of scrutinizing the quality and clarity of the scientific content in the manuscript and providing constructive criticism to help authors improve it. From the editor's perspective, feedback on a manuscript should indicate if the conclusions are new, if the study builds upon the existing literature, and above all assess if the evidence presented supports the conclusions.

On the question of "How to differentiate a poor review from a good one?", the panelists' collective reply was: $A$ good review demands useful and constructive criticism that identifies the strengths and weaknesses of a manuscript and gives recommendations with supporting justifications. As a reviewer, never go by dogmas and don't reject new ideas, if they are supported with data and systematic methodology. If the work is promising, but has not attained its best form, insist that authors take on the burden of more work to justify their novel ideas and research. Always be polite, objective and respectful to the author(s), regardless of whether you recommend the editor accepts or rejects the manuscript.

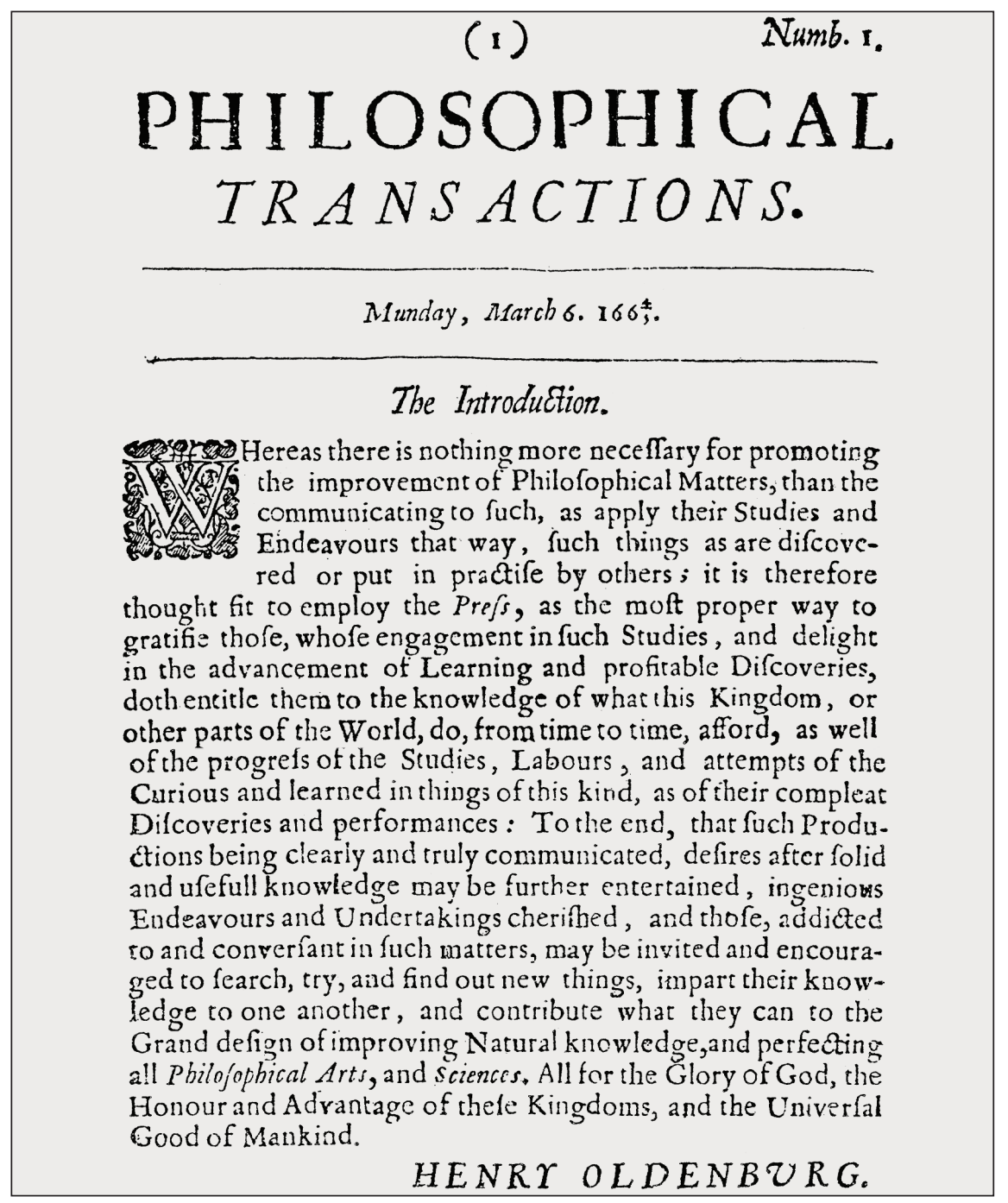

Figure 1: Introduction by Henry Oldenburg to the first issue of the Philosophical Transactions of the Royal Society (Oldenburg 1665)

A major issue for editors is finding suitable reviewers, as often the best-known experts in the field lack time. Nevertheless, it is fine to politely turn down the opportunity of reviewing a paper if you lack the time or the expertise the paper demands, or in the event of conflicting research interests. On the other hand, if you agree to do a review, you should keep your word and not decline the responsibility after several months of doing nothing with the manuscript.

The experienced referees on the panel reminded young scientists to be aware of the time pressures involved in reviewing. A thorough review of a paper takes a minimum of two to three days depending on one's efficiency and ability. Anticipating this pressure allows one to set aside ample time to read the paper and let the ideas sink in for a few days, before writing the review. This process helps sharpen one's ideas and thinking on the issues covered in the manuscript.

While it remains important that the authors cite the most recent papers relevant to the study, it is equally important to check if the authors cite the original pioneer works. In case you do not have access to the references the authors cite, you can ask for the papers from the editors rather than provide a poorly informed review.

Therefore, working on the review of a manuscript ahead of the deadline allows time to build initial impressions, verify cited references and reserve sufficient time for constructive feedback, steps that ensure a thorough review. Finally, submitting the report on time also ensures a smooth and efficient evaluation, and makes the 
new results swiftly available, to the benefit of science overall.

Ethics are a critical aspect in the art of reviewing, and an area in which young reviewers may need to develop. As a reviewer, one has the moral responsibility to put aside one's own research and publication interests, be honest and fair with the authors and consider the interests of the respective journal. The same is true for an editor or reviewer while dealing with conflicting reviews or accepting risky ideas. A test of one's integrity as a reviewer is whether or not you are able to put your name to the review, i.e. disclose your identity.

To ensure the editor can build an adequate assessment of the reviews, it is crucial that the reviewer clearly states which topics are outside his or her area of expertise. This allows the editor to identify additional experts, if needed. One should not shy away from providing detailed reviews, so that a paper can be improved to near perfection. This can include providing grammar and language amendments if possible. However, the main task of a reviewer is to evaluate the science of a study and not necessarily correct the language of the manuscript. Instead of spending time correcting spelling mistakes at the expense of evaluating the scientific content, the reviewer can mention the need for copy-editing to the editor.

Although demanding and time-consuming, reviewing manuscripts provides a unique opportunity to improve one's critical thinking and writing skills, stay updated on cutting-edge research techniques and ensure the quality and integrity of published science. This interactive session on "The Art of Reviewing" brought to light that about half of the $\sim 80$ early-career participants had reviewed papers either on behalf of their supervisors or directly for journals; however, most of them had never received formal training in reviewing. Consequently, the young scientists unanimously expressed the wish for formal training in reviewing as part of their doctoral education.
To conclude, the guiding line for a scientist should be "publish or perish"! But at the end of this session, we found a new one: "Peer review: love it or hate it, it's an integral part of every scientist's life." (Welsh 2010). So do not panic if an editor picks you to be the chosen one!

Additional information on the art of reviewing is available in published articles, e.g. Smith 1990; Provenzale and Stanley 2006; Rosenfeld 2010, and on these dedicated websites: users. ecs.soton.ac.uk/hcd/reviewing.html;

bcl.hamilton.ie/ barak/how-to-review.html; elsevier.com/reviewers/home;

councilscienceeditors.org/i4a/pages/index. cfm?pageid $=3331$

\section{References}

Oldenburg H (1665) Philosophical Transactions 1: 1-22 Provenzale JM, Stanley RJ (2006) Journal of Nuclear Medicine Technology 34: $92-99$

Rosenfeld RM (2010) Otolaryngology - Head and Neck Surgery 142: 472486

Smith AJ (1990) Computer 23: 65-71

Welsh J (2013) Discoblog: Year's Best Peer Review Comments: Papers That "Suck the Will to Live", blogs.discovermagazine.com/discoblog/2010/12/15/years-best-peer-review-comments-papersthat-suck-the-will-to-live/

\title{
The Art of Data Sharing: key in future climate science
}

\author{
Aurora Elmore ${ }^{1}$, F. Lehner ${ }^{2}$ and J. Franke ${ }^{2}$ \\ 'Department of Geography, Durham University, UK; aurora.elmore@durham.ac.uk \\ 2Oeschger Centre for Climate Change Research, University of Bern, Switzerland
}

A $t$ the PAGES Young Scientists Meeting, 11-12 February 2013, in Goa, India, 79 young researchers from around the world gathered to discuss research, to network, and to exchange ideas for the future of climate research. Initiated by a talk on "The Art of Data Sharing" given by David Anderson, head of the World Data Center for Paleoclimatology at the National Oceanic and Atmospheric Administration (NOAA), a lively discussion arose on the benefits and potential of data sharing for future research.

Fortunately, many researchers already upload their data and computer code to an Internet database to be available for future projects. Therefore, a wealth of databases and software exist that are open and easily accessible (see Box 1). These include data from classical proxy archives such as tree rings, ice cores, lake and marine sediments, as well as model output, reanalysis, observations and a multitude
Box 1: Examples of databases, software, and sample repositories.

The number of databases, open-source software and repositories is growing, providing extensive resources for scientists to engage in data-intensive research.

\section{Databases}

Pangaea, Data publisher for Earth \& Environmental sciences, www.pangaea.de World Data Center for Paleoclimatology, www.ncdc.noaa.gov/paleo Neotoma, A paleoecology database and community, www.neotomadb.org

JANUS, Data from the Integrated Ocean Drilling Program, www-odp.tamu.edu/database Core Curator's Database, the Index to Marine and Lacustrine Samples, www.ngdc.noaa. gov/mgg/curator

PAGES list of databases, www.pages-igbp.org/my-pages/data

Software

Calib, the radiocarbon calibration program, $h$ ttp://calib.qub.ac.uk/calib Analogue, Analogue and weighted-averaging methods for paleoecology, http://analogue.r-forge.r-project.org

Singular Spectrum Analysis, A toolkit for spectral analysis, www.atmos.ucla.edu/tcd/ssa Ocean Data View, a software package for the exploration and analysis of oceanographic and other data, $h$ ttp://odv.awi.de

KNMI Climate Explorer, an online tool to visualize and analyze climate data with a large ready-to-use database, climexp.knmi.nl 